\title{
Idade U-Pb do dique sienítico Anurí, sul da Bahia: magmatismo alcalino-potássico paleoproterozóico e sua implicação para a orogenia transamazônica no Cráton do São Francisco
}

\author{
Herbet Conceição ${ }^{1}$, Maria de Lourdes da Silva Rosa ${ }^{1,2}$, Felix Oberli ${ }^{3}$ \& Débora Correia Rios ${ }^{1}$
}

\begin{abstract}
Resumo O Dique Sienítico Anuri $\left(72 \mathrm{~km}^{2}\right)$ é o representante sul de um alinhamento N-S, com cerca de $1.000 \mathrm{~km}$ de extensão, de grandes diques de sienito que ocorrem na região leste da Bahia. Ele, como os demais, é constituído essencialmente por sienito hipersolvus com afinidade ultrapotássica, que guarda evidências de sua diferenciação pela presença de cumulatos máfico-ultramáficos ricos em apatita. Sua idade de cristalização de $2095 \pm 4 \mathrm{Ma}\left(\mathrm{U}_{-} \mathrm{Pb}_{\text {zirč̃o }}\right)$ superpõe àquelas obtidas para os outros diques de sienito, indicando que as intrusões desses corpos se processaram de forma sincrônica, após o clímax da Orogenia Transamazônica. Os dados geoquímicos revelam que esses sienitos apresentam-se enriquecidos em $\mathrm{Ba}, \mathrm{Sr}, \mathrm{P}$ e ETRLeves, constantes vales em $\mathrm{Ti}$ e $\mathrm{Nb}$, indicando uma fonte mantélica afetada por subduç̧ão. As razões dos isótopos iniciais $\mathrm{Sr}$ e os valores de $\varepsilon_{\mathrm{Nd}}$ apontam para um manto anômalo do tipo EMI. Esses dados sugerem que, ao final da Orogenia Transamazônica, no Cráton do São Francisco, foram reunidas condições particulares que propiciaram a geração de magmas alcalinos a partir da fusão de manto enriquecido do tipo EMI.
\end{abstract}

Palavras-chave: sienito, U-Pb zircão, Cráton do São Francisco, Bahia.

\begin{abstract}
U-Pb Age of the Anuri Dyke: Paleoproterozoic Potassic Alkaline Magmatism and Implications for the Transamazonic Orogeny in the São Francisco Craton. The Anuri Syenitic Dyke (72 $\mathrm{km}^{2}$ ) is the south representant of a $1000 \mathrm{~km} \mathrm{~N}-\mathrm{S}$ alignment of syenitic dykes which occur at the East Bahia. As the others bodies, Anuri is essentially composed of hypersolvus ultrapotassic syenites, which show the records of its diferentiation by the presence of mafic-ultramafic apatite-rich cumulates. Its crystallization age of $2095 \pm 4 \mathrm{Ma}\left(\mathrm{U}-\mathrm{Pb}_{\text {ziccão }}\right)$ is quite similar with results obtained for the other syenitic dykes, which suggest that their intrusions occur almost at the same time, sincronically, after the Transamazonic Orogeny climax. The geochemical data reveal that Anuri syenites are Ba, Sr, P, LREE enriched and show negative anomalies of Ti and $\mathrm{Nb}$, suggesting a mantelic source subduction related. The initial $\mathrm{Sr}$ ratio and $\varepsilon_{\mathrm{Nd}}$ values confirms the presence of this anomalous mantle. These data suggest that at the end of Transamazonic Orogeny, at the São Francisco Craton, there were particular conditions which allow the generation of alkaline magmas through the melting of an EMI reservoir.
\end{abstract}

Keywords: syenite, U-Pb zircon, São Francisco Craton, Bahia.

INTRODUÇÃO Os projetos de cartografia geológica regional realizados no estado da Bahia (p.ex. Silva Filho et al. 1974, 1977) reúnem uma vasta documentação sobre as rochas arqueano-paleoproterozóicas do embasamento do Cráton do São Francisco, que permitiram a individualização de numerosas entidades geológicas. Nesses estudos foram cartografados na parte leste da Bahia vários corpos tabulares de sienito com orientação NS encaixados em terrenos polimetamórficos e submetidos a metamorfismo de alto grau (Fig. 1). Os terrenos metamórficos dessa região foram reunidos por Mascarenhas (1979) sob a terminologia de Cinturão Móvel Costeiro Atlântico (granulíticos), núcleos arqueanos (gnáissico-migmatíticos). Atualmente os terrenos granulíticos foram nomeados como Orógeno Itabuna-
Salvador-Curaçá (Barbosa \& Sabaté 2003).

Os diques de sienito distribuem-se por mais de $1.000 \mathrm{~km}$ (Fig. 1) e são representados pelos corpos de Itiúba $\left(1.800 \mathrm{~km}^{2}\right)$, a norte, Santanápolis $\left(180 \mathrm{~km}^{2}\right)$ e São Félix $\left(32 \mathrm{~km}^{2}\right)$, na parte central, e Anuri $\left(72 \mathrm{~km}^{2}\right)$, no sul. Esses corpos foram inicialmente interpretados como anteriores ao evento granulítico (Figueiredo 1981) devido, provavelmente, a presença de estrutura gnáissica, que se expressa pela orientação de minerais e de níveis máficos. Atualmente, com a ampliação dos conceitos da reologia de magmas tem-se conhecimento que, a depender da viscosidade, taxa de cristalização e ambiência tectônica, rochas ígneas podem possuir estruturas que lembram aquelas tectônicas adquiridas durante o metamorfismo regional, porém elas preservam

1 - Laboratório de Petrologia Aplicada à Pesquisa Mineral, Centro de Pesquisa em Geofísica e Geologia, IGEO, UFBA, Salvador (BA), Brasil. E-mail: herbet@ufba.br, debora@cpgg.ufba.br, lourdes@cpgg.ufba.br

2 - Pesquisadora do PRODOC, CAPES, Curso de Pós-Graduação em Geologia, UFBA, Salvador (Ba), Brasil.

3 - Inst. Isotopengeologie/Mineral. Zürich. E-mail: oberli@erdw.ethz.ch 
a composição magmática dos minerais.

A disposição dos diques de Itiúba e Anuri (Fig. 1), que ocupam os extremos desse alinhamento, é considerada estratégica para a compreensão do significado geodinâmico desse plutonismo alcalino no contexto da Orogenia Transamazônica na parte leste do Cráton do São Francisco.

O Dique Sienítico Itiúba, o maior dentre esses corpos, é de natureza hipersolvus, alcalino-potássica, com afinidade ultrapotássica (Conceição 1993), e a sua colocação é considerada como posterior ao pico do metamorfismo granulítico (Conceição et al. 2003). As estruturas (gnáissica, orientação de cristais e autólitos) encontradas nesse corpo são interpretadas como produtos da cristalização sob forte atuação de fluxo magmático, capaz de promover segregação e acumulação da paragênese cristalizada precocemente (diopsídio e Fapatita) sob a forma de camadas, podendo, localmente, ser retrabalhada pelo mesmo fluxo, gerando os autólitos de cumulatos máfico-ultramáficos (Conceição 1990). A idade de cristalização desse sienito é de $2.095 \pm 5 \mathrm{Ma}$, sendo interpretada como marcadora do período tardio da Orogenia Transamazônica no leste da Bahia (Conceição et al. 2003). Feições geológicas e petrográficas similares são descritas por Rosa \& Conceição (1995) para o Dique Sienítico São Félix.

Este trabalho apresenta e discute os dados geológicos, petrográficos, geoquímicos e geocronológicos para o Dique Sienítico Anuri integrando-os aos disponíveis para os diques de Itiúba e São Félix, enfocando o significado do magmatismo alcalino-potássico paleoproterozóico no contexto da Orogenia Transamazônica na parte leste da Bahia.

ORÓGENO ITABUNA-SALVADOR-CURAÇÁ O Orógeno Itabuna-Salvador-Curaçá (OISC), com aproximadamente $170.000 \mathrm{~km}^{2}$ e orientado N-S (Fig. 1), constitui uma unidade geotectônica importante no Cráton do São Francisco. Ele reúne rochas metamórficas arqueano-paleoproterozóicas e vários corpos graníticos. As rochas metamórficas foram polideformadas e submetidas às condições da Fácies Granulito durante o período Paleoproterozóico (p.ex. Silva et al. 2002). As diferentes unidades que constituem esse orógeno mostram-se dispostas como faixas condicionadas a sua geometria. Em sua parte norte elas exibem estrutura em flor positiva, que é admitida como resultante do processo colisional envolvendo os núcleos arqueanos Remanso e Serrinha (Padilha \& Melo 1991). Os dados geoquímicos dos metamorfitos evidenciam a presença de suítes cálcio-alcalinas de ambiente colisional (Teixeira 1997), existindo tipos com afinidade toleí́tica cujo significado é objeto de debate. Na parte sul do OISC a estruturação NS de seus metamorfitos é adquirida, segundo Barbosa et al. (2003), como resultado de sucessão de eventos colisionais com vergência de leste para oeste. Nesses terrenos dominam rochas de suítes cálcio-alcalinas, existindo rochas com afinidades toleiítica interpretadas como restos de crosta oceânica. Magmatismo alcalino instalaram-se no interior do OISC sob a forma de diques,

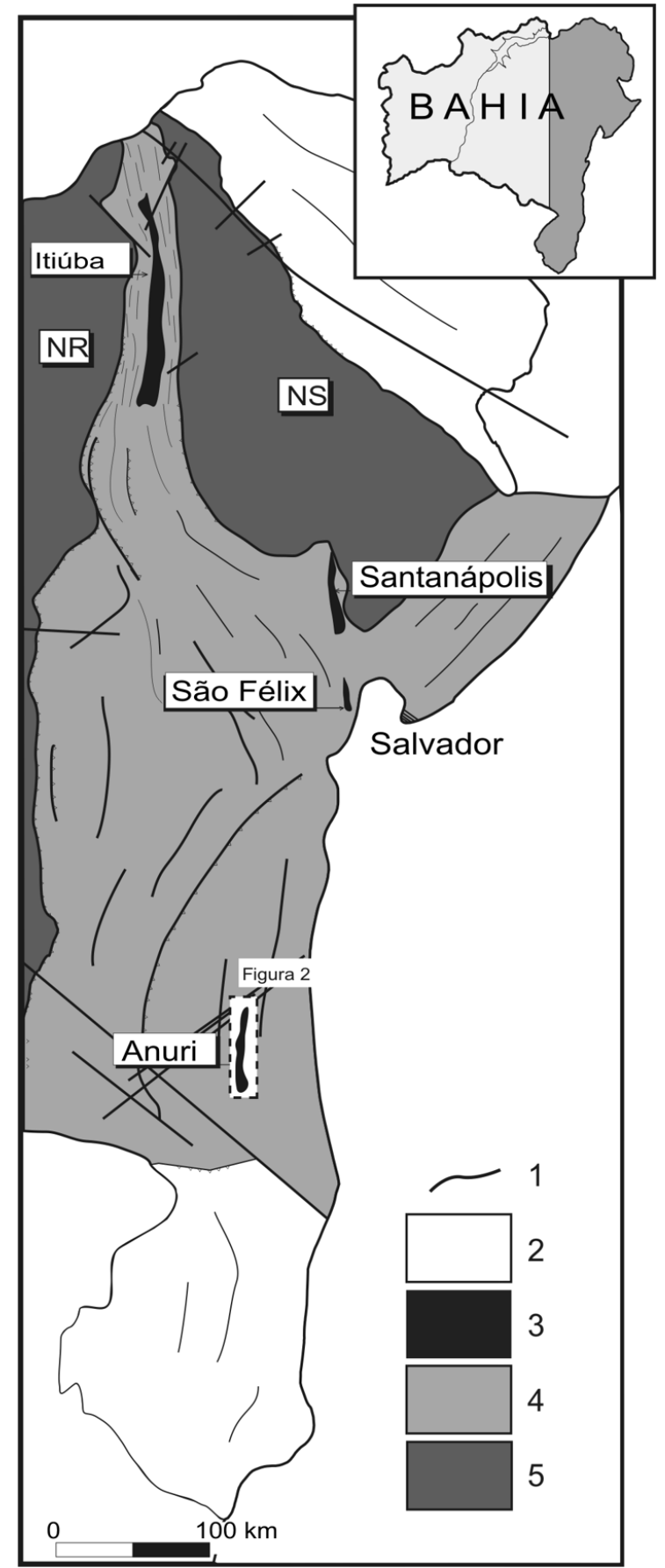

Figura 1 - Contorno geográfico do leste do Estado da Bahia com a localização dos núcleos arqueanos de Serrinha (NS) e Remanso (NR), diques de sienito Itiúba, Santanápolis, São Félix e Anuri. Fraturas e falhas (1), terrenos neoproterozóicos (2), diques de sienito paleoproterozóicos (3), terrenos granulíticos arqueano-paleoproterozóicos (4) e núcleos arqueanos (5)

com afinidade ultrapotássica, ou como maciços graníticos, com afinidade shoshonítica. Em ambos os casos, essas intrusões mostram-se controladas por estruturas tectônicas pretéritas (Conceição \& Otero 1996). 
DADOS GEOLÓGICOS, PETROGRÁFICOS E MINERALÓGICOS O Dique Sienítico Anuri (DSA), identificado por Silva Filho et al. (1974), faz contato por falhas com rochas granulíticas (Fig. 2), as quais, ocasionalmente, ocorrem como xenólitos angulares nas regiões próximas aos contatos. O DSA é constituído essencialmente por sienito de cor cinza com tonalidade violácea, existindo de forma esporádica diques de sienito de cor branca, com até $1 \mathrm{~m}$ de espessura, e autólitos e leitos máficos isomodal, constituído essencialmente por diopsídio ( $90 \%$ em volume), ou gradacional, formado por diopsídio, edenita, flogopita, apatita e feldspato alcalino. A foliação de fluxo magmático subvertical é constante nessas rochas e se acentua na proximidade dos contatos, gerando estrutura gnáissica cuja orientação é condicionada a geometria do corpo (Conceição et al. 1996).

O sienito hipersolvus leucocrático perfaz $98 \%$ do DAS. Ele é essencialmente constituído por prismas de feldspato alcalino rico em inclusões de minerais máficos. Esses cristais exibem geminação Carlsbad, são pertíticos, geralmente mostram-se coroados por cristais anédricos de albita $(<5 \% \mathrm{An})$, e guardam inclusões euédricas de diopsídio, ilmenita, anfibólio, F-apatita e Timagnetita. O diopsídio pobre em titânio $\left(0,3<\% \mathrm{TiO}_{2}\right)$, ocorre com forma subédrica e exibe coroa formada por edenita e magnetita. A edenita forma-se à custa do diopsídio e apresenta aumento de $\mathrm{MgO}$ do centro para a periferia, indicando aumento da fugacidade de oxigênio. A biotita, com $\mathrm{TiO}_{2}$ compreendido entre $2,6 \%$ e $3,4 \%$, mostra íntima associação com os outros minerais máficos. Os minerais acessórios são F-apatita, titanita, zircão, sulfeto (pirita>calcopirita), allanita e calcita.

Os leitos máficos com estrutura isomodal exibem contatos nítidos com o sienito encaixante, enquanto que os acamados mostram contatos bem definidos na base e difusos no topo. Eles representam acumulações de diopsídio pobre em $\mathrm{TiO}_{2}$ e F-apatita. Nos leitos acamados tem-se na base apatitito e diopsídio-apatita cumulato que evolui para apatita-diopsídio-ortoclásio cumulato no topo. Essa estruturação é similar àquela descrita por Conceição (1990) no Dique Sienítico Itiúba. Os minerais intercumulos são: biotita rica em $\mathrm{TiO}_{2}$ (3,7-5,6\%), hornblenda e, ocasionalmente, feldspato alcalino.

Diques de sienito hipersolvus verticais, com dimensões centimétircas, que cortam as rochas do DSA. São rochas hololeucocráticas e isotrópicas, e instalaram-se no sienito encaixante após ele adquirir foliação gnáissica.

GEOQUÍMICA Análises químicas representativas das rochas do DSA de Conceição et al. (1996) são apresentadas na tabela 1.

No diagrama TAS (Fig. 3) as rochas ocupam essencialmente o campo do latito, existindo algumas delas que se alocam nos campos dos shoshonito e traquito. Essas rochas posicionam-se no domínio das suítes alcalinas, exibem afinidade ultrapotássica e quando comparadas aos outros diques de sienito do leste da

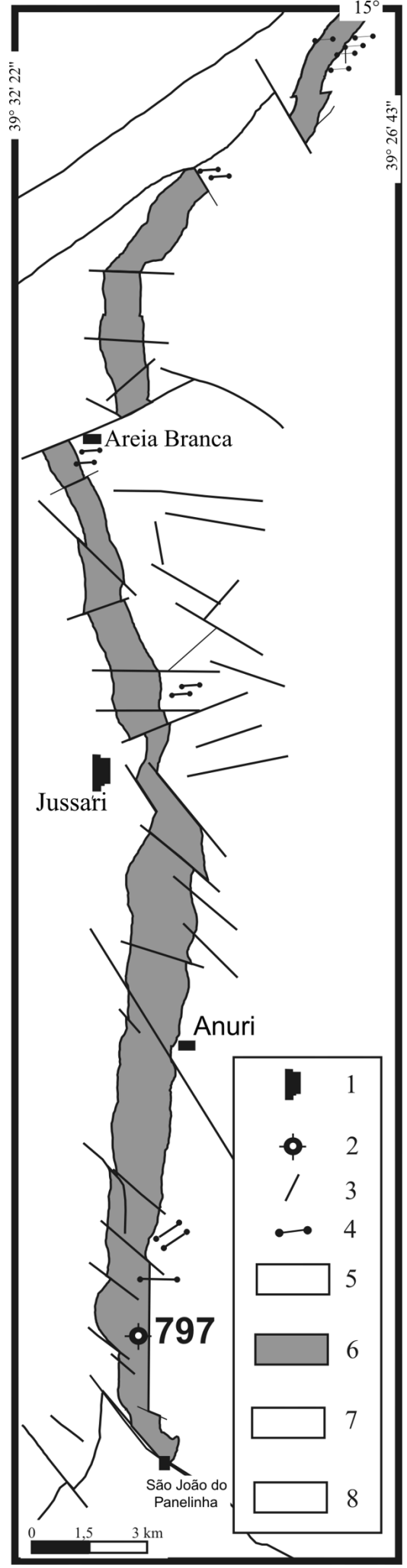

Figura 2 - Esboço geológico do Dique Sienítico Anuri com a localização da amostra utilizada para a determinação da idade U-Pb. Cidade [1], ponto analisado [2], falhas/fraturas [3], diques [4], zonas de cisalhamento [5], metassedimentos da Bacia do Rio Pardo [6], Dique Sienitico Anuri [7], granulitos [8]. 
Idade U-Pb do dique sienítico Anurí, sul da Bahia: magmatismo alcalino-potássico paleoproterozóico e sua implicação para a orogenia transamazônica no Cráton do São Francisco

Tabela 1 - Amostras representativas do Dique Sienítico Anuri. Leito Máfico (LM), sienito (S) e dique (D), após Conceição et al. (1996).

\begin{tabular}{|c|c|c|c|c|c|c|}
\hline & 800 & 816 & 810 & 797 & 804 & 796 \\
\hline & LM & S & $\mathrm{S}$ & S & S & $\mathrm{D}$ \\
\hline $\mathrm{SiO}_{2}(\%)$ & 51,70 & 53,50 & 55,30 & 58,50 & 62,50 & 62,00 \\
\hline $\mathrm{TiO}_{2}$ & 1,50 & 1,60 & 1,20 & 1,20 & 0,52 & 0,28 \\
\hline $\mathrm{Al}_{2} \mathrm{O}_{3}$ & 9,90 & 14,10 & 13,30 & 13,80 & 16,40 & 15,40 \\
\hline $\mathrm{Fe}_{2} \mathrm{O}_{3}$ & 1,90 & 5,40 & 3,60 & 4,70 & 2,30 & 1,50 \\
\hline $\mathrm{FeO}$ & 6,30 & 4,60 & 4,20 & 3,00 & 1,60 & 1,40 \\
\hline $\mathrm{MgO}$ & 7,70 & 3,50 & 3,40 & 2,60 & 1,60 & 1,50 \\
\hline $\mathrm{MnO}$ & 0,09 & 0,14 & 0,13 & 0,10 & 0,05 & 0,06 \\
\hline $\mathrm{CaO}$ & 9,10 & 6,30 & 5,60 & 4,50 & 1,70 & 3,00 \\
\hline $\mathrm{Na}_{2} \mathrm{O}$ & 1,40 & 2,60 & 2,60 & 3,10 & 4,00 & 4,50 \\
\hline $\mathrm{K}_{2} \mathrm{O}$ & 6,70 & 4,70 & 6,90 & 5,50 & 8,80 & 8,60 \\
\hline $\mathrm{P}_{2} \mathrm{O}_{5}$ & 2,20 & 1,50 & 1,60 & 1,10 & 0,32 & 0,45 \\
\hline $\mathrm{H}_{2} \mathrm{O}_{+}$ & 0,49 & 1,10 & 0,74 & 0,84 & 0,24 & 0,18 \\
\hline $\mathrm{CO}_{2}$ & 0,04 & 0,02 & 0,07 & 0,03 & 0,02 & 0,46 \\
\hline$\% \mathrm{~F}$ & 0,45 & 0,43 & 0,42 & 0,31 & 0,12 & 0,07 \\
\hline Total & 99,47 & 99,49 & 99,06 & 99,28 & 100,17 & 99,40 \\
\hline $\mathrm{V}(\mathrm{ppm})$ & 140 & 130 & 98 & 84 & 43 & 16 \\
\hline $\mathrm{Cr}$ & 194 & 57 & 73 & 61 & 39 & 10 \\
\hline Co & 50 & 50 & 28 & 22 & 17 & 22 \\
\hline $\mathrm{Ba}$ & 366 & 3470 & 4640 & 3400 & 3870 & 2710 \\
\hline $\mathrm{Ni}$ & 132 & 29 & 39 & 29 & 15 & 93 \\
\hline $\mathrm{Cu}$ & 80 & 95 & 50 & 56 & 12 & 296 \\
\hline $\mathrm{Rb}$ & 210 & 76 & 180 & 110 & 280 & 200 \\
\hline $\mathrm{Sr}$ & 1710 & 1360 & 2040 & 1780 & 2110 & 1920 \\
\hline Y & 50 & 64 & 36 & 42 & 16 & 81 \\
\hline $\mathrm{Zr}$ & 190 & 680 & 620 & 690 & 230 & 78 \\
\hline $\mathrm{Nb}$ & 5 & 14 & 8 & 11 & $<5$ & 8 \\
\hline Th & $<5$ & $<5$ & $<5$ & $<5$ & $<5$ & 140 \\
\hline $\mathrm{Ga}$ & $<5$ & 18 & 10 & 18 & 26 & 29 \\
\hline $\mathrm{Hf}$ & $<8$ & 15 & 10 & 18 & $<8$ & $<8$ \\
\hline $\mathrm{Cl}$ & 140 & 31 & 220 & 240 & 63 & 140 \\
\hline $\mathrm{La}$ & 231,2 & 150,6 & 151,1 & 143,9 & 50,0 & 560,2 \\
\hline $\mathrm{Ce}$ & 498,8 & 364,1 & 345,1 & 334,2 & 110,9 & 1202 \\
\hline $\mathrm{Nd}$ & 251,6 & 184,8 & 179,4 & 173,4 & 51,25 & 489,2 \\
\hline $\mathrm{Sm}$ & 37,71 & 28,59 & 30,47 & 25,58 & 8,01 & 66,87 \\
\hline $\mathrm{Eu}$ & 7,12 & 4,78 & 5,82 & 4,59 & 2,39 & 4,14 \\
\hline $\mathrm{Gd}$ & 22,23 & 16,73 & 17,78 & 14,74 & 4,79 & 37,71 \\
\hline Dy & 10,56 & 10,60 & 8,886 & 7,83 & 2,39 & 17,78 \\
\hline Но & 1,89 & 2,03 & 1,634 & 1,49 & 0,45 & 3,00 \\
\hline $\mathrm{Er}$ & 4,05 & 5,04 & 3,691 & 3,65 & 0,85 & 6,06 \\
\hline $\mathrm{Yb}$ & 1,96 & 3,68 & 1,805 & 2,29 & 0,52 & 2,42 \\
\hline $\mathrm{Lu}$ & 0,27 & 0,48 & 0,304 & 0,30 & 0,08 & 0,35 \\
\hline
\end{tabular}




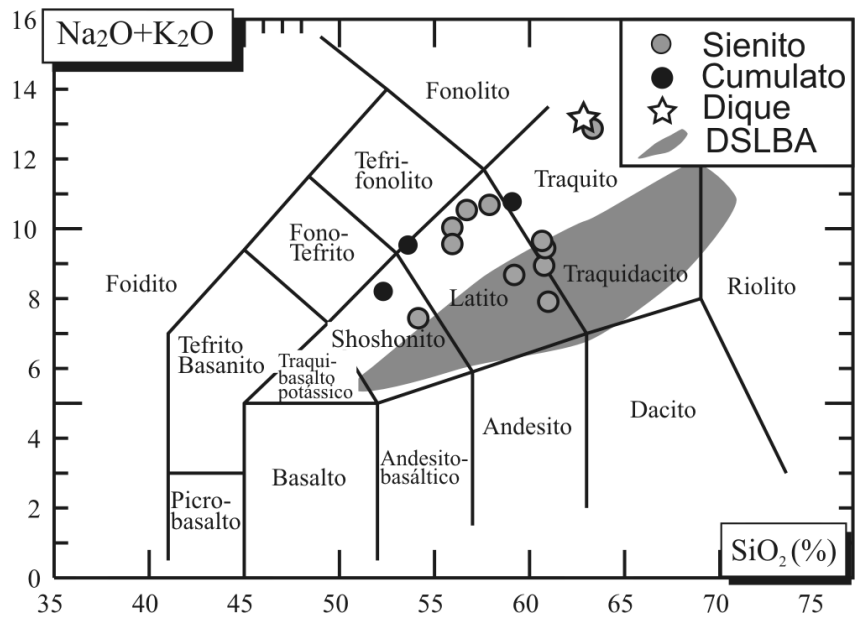

Figura 3 - Diagrama Total de Álcalis versus $\mathrm{SiO}_{2}$ (Le Bas et al. 1986) aplicado às rochas do Dique Sienítico Anuri com as recomendações de Le Maître et al. (2002) para a nomenclatura das rochas vulcânicas potássicas $\left(\mathrm{K}_{2} \mathrm{O}>\mathrm{Na}_{2} \mathrm{O}-2\right)$. Sienito (circulo vazio), leito máfco (circulo preto) e dique (estrela). A área achuriada corresponde à ocupada pelas rochas dos outros diques sienito do leste da Bahia (DSLBA; Conceição 1993).

Bahia apresentam com maior conteúdo total de álcalis (Fig. 3).

No sienito dominante os conteúdos de $\mathrm{SiO}_{2}$ estão compreendidos entre $53-62 \%, \mathrm{~K}_{2} \mathrm{O} 8,8-4,6 \%$ e a razão $\mathrm{K}_{2} \mathrm{O} / \mathrm{Na}_{2} \mathrm{O}$ entre 1,7 e 3,5 (Tab. 1). Eles apresentam altos conteúdos de $\mathrm{Ba}$ (4800-3300 ppm), Sr (2400$1000 \mathrm{ppm})$, EETR (900-200 ppm), Cl (290-31 ppm), F $(0,45-0,12 \%)$ e $\mathrm{P}_{2} \mathrm{O}_{5}(1,6-0,32 \%)$; moderados valores de $\mathrm{Rb}$ (76-280 ppm), Zr (230-690 ppm); e baixos de $\mathrm{Nb}(<5-14 \mathrm{ppm}), \mathrm{Y}(16-64 \mathrm{ppm}), \mathrm{Ni}(15-39 \mathrm{ppm})$ e $\mathrm{Cr}$ (39-62 ppm).

Nos leitos máficos têm-se olivina normativa $(0,7<\% \mathrm{Fo}<0,65), \mathrm{SiO}_{2}$ varia de $51-59 \%, \mathrm{MgO} 7,7-$ $4,1 \%, \mathrm{CaO} 9,1-4,8 \%, \mathrm{Al}_{2} \mathrm{O}_{3} 9,9-13,0 \%, \mathrm{~K}_{2} \mathrm{O}$ 6,7-7,20, razão $\mathrm{K}_{2} \mathrm{O} / \mathrm{Na}_{2} \mathrm{O}$ entre 4,8 e $2, \mathrm{Ba}(2140-336$ ppm), $\mathrm{Sr}$ (1710-1040 ppm), Rb (230-210 ppm), Zr (340-150 ppm), Nb (11-5 ppm), Y (50-29), Ni (132-78 ppm) e Cr (226-163 ppm). A análise do dique de sienito hololeucocrático [62\% $\mathrm{SiO}_{2}$, razão $\mathrm{K}_{2} \mathrm{O} / \mathrm{Na}_{2} \mathrm{O}$ igual a 1,9 , é rico em $\mathrm{K}_{2} \mathrm{O}(8,6 \%)$, Ba (2710 ppm), Sr (1920 ppm), Y $(81 \mathrm{ppm})$ e Th $(140 \mathrm{ppm})$ e somatório de ETR (2400 ppm)] com aegirina $(5,9 \%)$ e nefelina $(1,4 \%)$ normativas, revela o aumento da alcalinidade com a diferenciação do magma.

Os espectros de ETR dos sienito e leitos máficos são similares (Fig. 4), e marcados por enriquecimento em ETRLeves $\left(27<\mathrm{La}_{\mathrm{N}} / \mathrm{Yb}_{\mathrm{N}}<97\right)$ com fracas anomalias negativas em $\mathrm{Eu}\left(\mathrm{Eu} / \mathrm{Eu}^{*} 0,6-0,7\right)$. A semelhança é interpretada como produto de rochas que foram formadas a partir de um magma com mesmo grau de fracionamento.

As simulações de cristalização fracionada, realizadas por Conceição et al. (1996) para as rochas do DAS, demonstram ser possível explicar a evolução

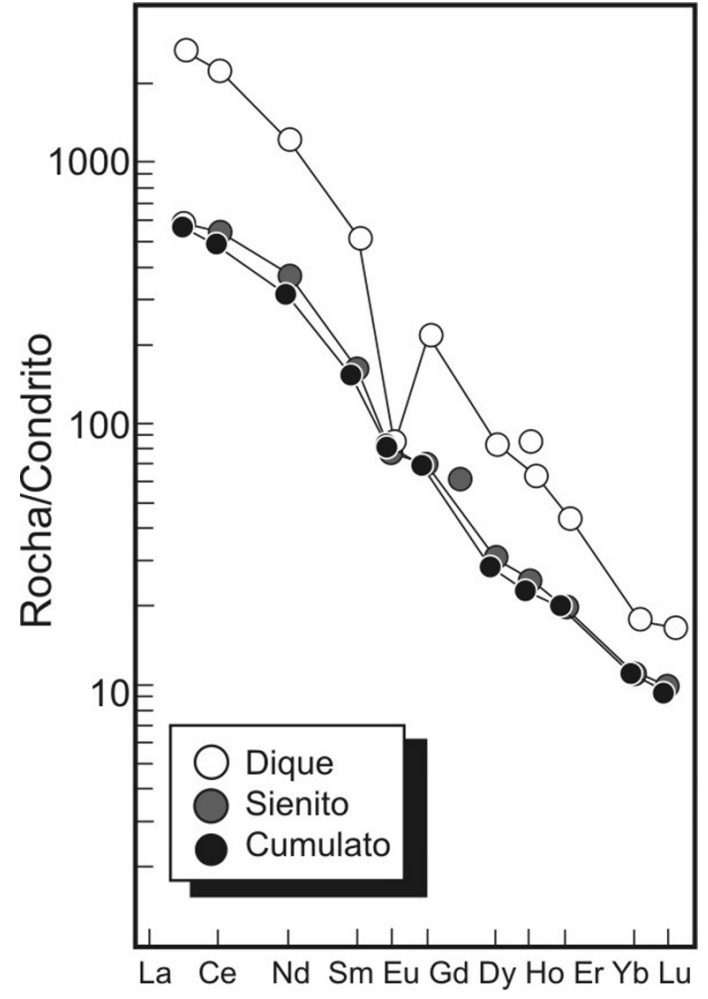

Figura 4 - Diagramas para os elementos terras raras, normalizado pelo Condrito $C 1$ de Evensen et al. (1978) aplicado às rochas do DSA.

geoquímica e as acumulações encontradas por processo de fracionamento. Esses mesmos autores chamaram a atenção para a incapacidade do magma latítico, que originou as rochas do DSA, de cristalizar plagioclásio e para o fato da mineralogia cristalizada precocemente ser constituída por apatita, diopsídio e biotita. Comportamento similar é descrito por Rosa et al. (2001) para o Dique Sienítico São Félix e interpretado como a expressão da natureza lamprofírica do magma.

GEOCRONOLOGIA U-Pb Selecionou-se a amos-

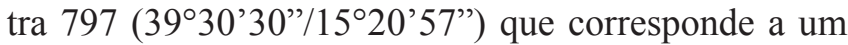
álcali-feldspato sienito para o estudo geocronológico, utilizando-se a técnica de diluição isotópica em monocristais de zircão. A rocha foi submetida aos métodos clássicos para separação de minerais (britagem, moagem, separação magnética, líquidos densos). Os cristais de zircão da fração menos magnética foram utilizados no estudo, eles possuíam coloração castanha clara, tamanhos entre 30 a $45 \mu$ e não apresentavam inclusões ou fraturas.

As análises isotópicas foram realizadas nos laboratórios do Instituto de Geologia Isotópica e Recursos Minerais do ETH (Zurique-Suíça). Os procedimentos laboratoriais do ETH para as determinações U-Pb monocristais de zircão, iniciam-se pela limpeza desses com álcool e acetona no ultra-som. Os cristais são pesados e depois são levados a placa aquecedora com $\mathrm{HNO}_{3}(1 \mathrm{M})$ e $\mathrm{HCl}(5 \mathrm{M})$, durante 10 e 30 minutos, respectivamente. 
Em seguida, eles são lavados por três vezes com águamilli-Q e acondicionados em um à bomba de teflon onde é colocado e pesado o spike (uma mistura de ${ }^{233} \mathrm{U},{ }^{235} \mathrm{U}$, ${ }^{230} \mathrm{Th}$ e $\left.{ }^{205} \mathrm{~Pb}\right)$. Em seguida adiciona-se HF $(300 \mu \mathrm{L}) \mathrm{e}$ $\mathrm{HNO}_{3}(8 \mu \mathrm{L})$ em cada bomba e leva-se no forno, por um período de uma semana, a uma temperatura de $215^{\circ} \mathrm{C}$. Posteriormente é realizada a separação química de $\mathrm{U}$, $\mathrm{Th}$ e $\mathrm{Pb}$, em colunas Z-RCl-50 com resina (Biorad $A G$ 1-X8, $\mathrm{Cl}^{-}$) entre 100-200 mesh, para a coleta do $\mathrm{U}, \mathrm{Pb}$ e Th. As leituras das razões isotópicas desses elementos foram efetuadas em espectrômetro de massa FINNIGAM MAT 262. O cálculo da idade foi feito utilizandose o programa Isoplot (Ludwing 2001).

Os três cristais de zircão analisados (Tab. 2), quando dispostos no diagrama U-Pb concórdia, forneceram uma idade de $2095 \pm 4$ Ma, MSWD= 1,8 (Fig. 5), que é interpretada como a da cristalização do Dique Sienítico Anuri, e que coincide com a dos outros diques de sienitos do OISC.

GEOQUÍMICA ISOTÓPICA As razões isotópicas de $\mathrm{Sr}$ e $\mathrm{Nd}$, assim como os conteúdos desses elementos foram determinadas por diluição isotópica, em três amostras representativas do DAS. Esses dados foram obtidos na Université Blaise Pascal, França, utilizandose espectrômetro de massa VG ISOMASS 54E, para maiores detalhes consultar Rosa (1999). Os erros das determinações isotópicas de ${ }^{87} \mathrm{Sr} /{ }^{86} \mathrm{Sr}$ e ${ }^{143} \mathrm{Nd} /{ }^{144} \mathrm{Nd}$ são indicadas como $2 \sigma$. As razões iniciais de estrôncio $\left(\mathrm{Sr}_{\mathrm{i}}\right)$ e os valores do épislon neodímio $\left(\varepsilon_{\mathrm{Nd}}\right)$ foram calculados para a idade de $2095 \mathrm{Ma}$, utilizando-se para as idades modelos valores ${ }^{143} \mathrm{Nd} /{ }^{144} \mathrm{Nd}_{\text {CHUR }}=0,512638 \mathrm{e}$ ${ }^{147} \mathrm{Sm} /{ }^{144} \mathrm{Nd}_{\text {CHUR }}=0,1967$. As constantes de decaimento utilizadas foram àquelas recomendadas por Faure (1986).

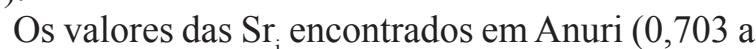
$0,707)$ são mais elevados quando comparadas a dos outros corpos de sienito $(0,701-0,704)$ do leste da Bahia. Esses dados quando lançados no diagrama $\mathrm{Sr}_{i}$ versus $\varepsilon_{\mathrm{NdT}}$ (Fig. 6) posicionam-se no quadrante do manto enriquecido EMI, similar ao posicionamento de outros corpos alcalinos paleoproterozóicos do Cráton do São
Francisco (Fig. 6).

DISCUSSÃO E CONCLUSÃO A forma em dique orientada NS a que estão dispostos os corpos de sienito no leste da Bahia é indicativa que seus magmas aproveitaram de espaço estruturado por ação tectônica capaz de gerar grandes condutos retilíneos. Os dados químicos de minerais obtidos dos sienitos (Conceição 1990, Rosa 1994, Conceição et al. 1996) indicam que eles se cristalizaram na interface epizona-mesozona, compatíveis, portanto, com as condições reológicas para proporcionarem a resposta relativamente frágil observada nas rochas metamórficas. Por outro lado, a presença de ortopiroxênio nos metamorfitos encaixantes dos corpos de sienito sugere que o metamorfismo regional atingiu condições da Fácies Granulito, a qual é admitida como o clímax da Orogênese Transamazônica nessa parte do Cráton do São Francisco (Silva et al. 2002). A ausência de paragênese metamórfica nas rochas dos diques de sienito, assim como das deformações encontradas em suas encaixantes permitem ampliar para todos os corpos de sienito do leste da Bahia a hipótese levantada por Conceição et al. (2003), a qual propõe que a colocação do Dique Sienítico Itiúba se processe em período posterior ao clímax do metamorfismo da Orogenia Transamazônica, em fase distensiva.

Os dados estruturais aliados às determinações geocronológicas disponíveis para os terrenos granulíticos da parte leste do Cráton do São Francisco indicam que eles não sofreram efeitos tectônicos importantes, tendo permanecido estáveis após a Orogenia Transamazônica (Alkmim 2004). Essa hipótese encontra suporte na continuidade das unidades geológicas cartografadas do OISC. Esses fatos permitem propor que a posição e geometria atual dos diques de sienito são muito próximas daquelas quando de suas colocações, tendo suas exposições, provavelmente, sido ampliadas por efeitos de denudação.

A idade obtida para o Dique Sienítico Anuri, de $2.095 \pm 4 \mathrm{Ma}$, é considerada como a de sua cristalização. Ela é similar a aquelas obtidas para os diques sieníticos de Itiúba (2.095 \pm 5 Ma, Conceição et al. 2003)

Tabela 2 - Dados isotópicos U-Pb de monocristais de zircão do Dique Sienítico Anuri. Valores medidos (obs) e isótopos radiogênicos (rad). [1] Medida com uma precisão de $\pm 0,3 \mu \mathrm{g}$ (2 sigmas de reprodutibilidade) usando uma balança ultra-micro. [2] Concentração do chumbo radiogênico no zircão analisado. [3] Concentração do chumbo comum no zircão analisado (corrigido pelo branco analítico). [4] Conteúdo do chumbo comum no zircão analisado (incluindo o branco analítico).

\begin{tabular}{|c|c|c|c|c|c|c|c|c|c|c|c|c|}
\hline Cristal & $\operatorname{Massa}^{[1]}$ & $\mathrm{U}$ & $\mathrm{Pb}^{[2]}$ & $\mathrm{Pb}^{[3]}$ & $\mathrm{Pb}^{[4]}$ & $\begin{array}{l}{ }^{208} \mathrm{~Pb} / \\
{ }^{204} \mathrm{~Pb}\end{array}$ & $\begin{array}{l}{ }^{207} \mathrm{~Pb} / \\
{ }^{206} \mathrm{~Pb}\end{array}$ & $\begin{array}{l}{ }^{207} \mathrm{~Pb} / \\
{ }^{235} \mathrm{U}\end{array}$ & $\begin{array}{l}{ }^{207} \mathrm{~Pb} / \\
{ }^{238} \mathrm{U}\end{array}$ & $\begin{array}{l}{ }^{207} \mathrm{~Pb} / \\
{ }^{206} \mathrm{~Pb}\end{array}$ & $\begin{array}{l}{ }^{207} \mathrm{~Pb} / \\
{ }^{235} \mathrm{U}\end{array}$ & $\begin{array}{l}{ }^{207} \mathrm{~Pb} / \\
{ }^{238} \mathrm{U}\end{array}$ \\
\hline & (mg) & (ppm) & (ppm) & (ppm) & (pg) & (obs) & (rad) & (rad) & (rad) & Idade [Ma] & Idade [Ma] & Idade [Ma] \\
\hline 04 & 1,2 & 447 & 193 & 9,28 & 12,7 & 936,7 & $0,12958 \pm 3,0$ & $6,779 \pm 30$ & $0,3794 \pm 13$ & $2092,2 \pm 4,0$ & $2082,9 \pm 39$ & $2073,6 \pm 62$ \\
\hline 24 & 1,8 & 319 & 137 & 0,638 & 2,7 & 4783 & $0,12981 \pm 1,7$ & $6,814 \pm 28$ & $0,3807 \pm 14$ & $2095,3 \pm 2,4$ & $2087,5 \pm 37$ & $2079,7 \pm 66$ \\
\hline 30 & 1,6 & 446 & 188 & 0,445 & 2,2 & 7021 & $0,12972 \pm 1,5$ & $6,681 \pm 28$ & $0,3736 \pm 13$ & $2094,2 \pm 2,0$ & $2070,1 \pm 34$ & $2046,1 \pm 62$ \\
\hline
\end{tabular}




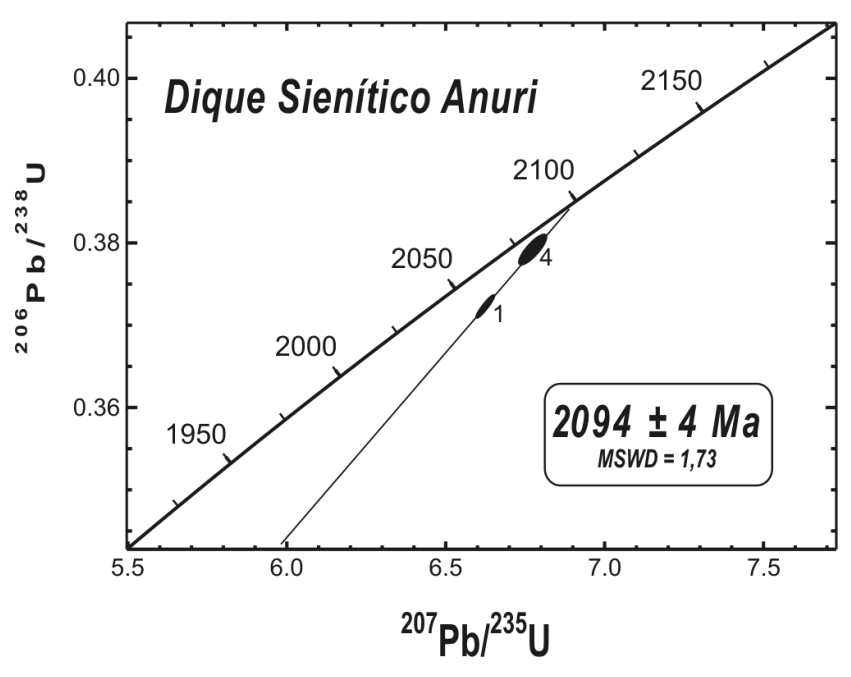

Figura 5 - Diagrama da concórdia U-Pb para aos cristais de zircão do Dique Sienítico Anuri.

e São Félix (2.098 \pm 1 Ma, Rosa et al. 2001), indicando que as colocações desses magmas ocorram de forma sincrônica, levando-se em conta os erros analíticos. Esses dados evidenciam a existência de um único evento de magmatismo alcalino-potássico paleoproterozóico nessa região, condicionado ao longo de um alinhamento de mais de $1.000 \mathrm{~km}$. Por outro lado, o alinhamento descontínuo dos diques, que se acomodam a geometria observada no OISC, é compatível com a dinâmica de transcorrência no orógeno, e explica convenientemente o alívio da tensão regional posterior à colisão paleoproterozóica entre os núcleos Remanso e Serrinha. A presença de outros corpos alcalinos paleoproterozóicos, como Batólito Guanambi $\left(6.000 \mathrm{~km}^{2}, 2.050 \mathrm{Ma}\right.$, Rosa 1999), Complexo Carbonatítico de Angico dos Dias (2.011 $\pm 6 \mathrm{Ma}$, Silva et al. 1988), sienitos no Núcleo Serrinha (Conceição et al. 2002, Rios 2002) e Sienito de Piranga, em Minas Gerais (2.036 \pm 4 Ma, JordtEvangelista et al. 2000) indicam que durante o período tardio da Orogenia Transamazônica, reuniram-se condições favoráveis para a geração de amplo magmatismo alcalino no Cráton do São Francisco.

Analisando-se conjuntamente os dados químicos de rochas dos diques do leste da Bahia (Fig. 7) constata-se que eles apresentam várias feições em comum, onde se destacam: (1) constantes vales em $\mathrm{Nb}$ e Ti in-

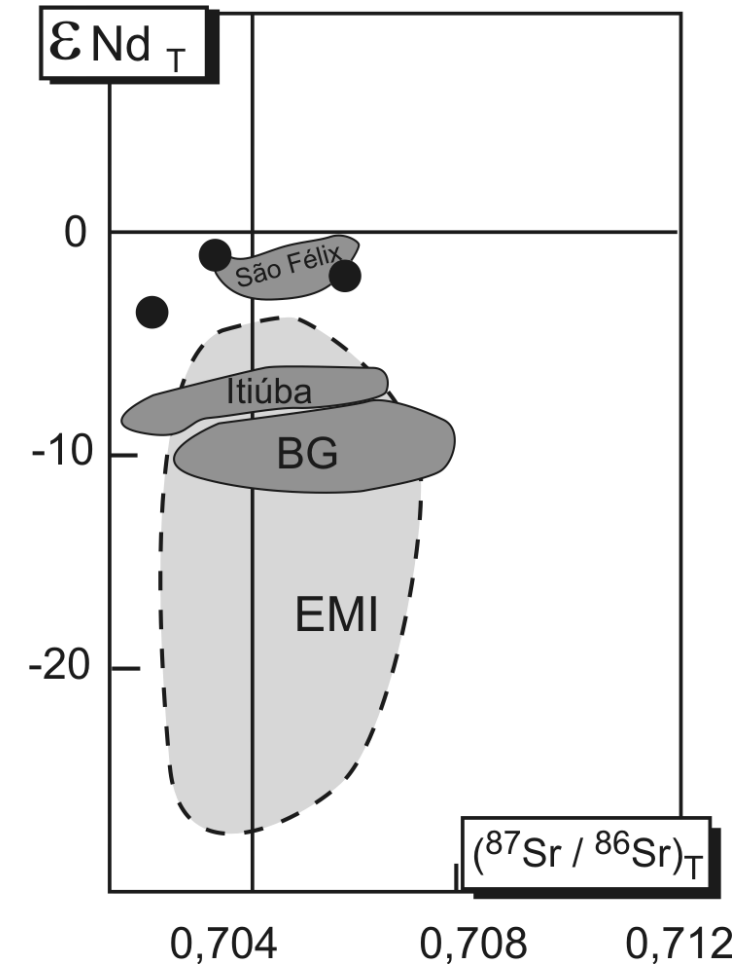

Figura 6 - Gráfico da razão inicial Sr versus $\varepsilon_{N d(T)}$ para os sienitos DSA, comparados com outras ocorrências de rochas potássicas e ultrapotássicas no Cráton do São Francisco: Conceição et al. (1997) [Itiúba - 2095 Ma], Rosa et al. (2001) [São Félix - 2098 Ma], Rosa et al. (2000) [Batólito Guanambi - 2050 Ma]. Campo EMI segundo Rollinson (1993).

dependentes do grau de evolução das rochas, sugerindo que essa feição retrate a assinatura da fonte e não influenciada pelo o processo de fracionamento, sendo usualmente interpretada como de componente de subducção (p.ex. Pearce et al. 1984); (3) os conteúdos elevados em elementos incompatíveis em magmas básicos (Ba, Sr, ETRLeves), presentes tanto nos produtos de acumulação quanto nos termos mais diferenciados, indicam que o magma que os originou apresentavam assinatura geoquímica similar.

Os valores de $\varepsilon_{\mathrm{NdT}}$ e $\mathrm{Sr}_{\mathrm{i}}$ (Tab. 3) para os dife-

Tabela 3 - Dados isotópicos Rb-Sr e Sm-Nd, em rocha total, do Dique Sienítico Anuri.

\begin{tabular}{l|c|c|c|c|c|c|c|c|c|c|c}
\hline Amostra & $\begin{array}{c}\mathrm{Rb} \\
(\mathrm{ppm})\end{array}$ & $\begin{array}{c}\mathrm{Sr} \\
(\mathrm{ppm})\end{array}$ & ${ }^{87} \mathrm{Rb} /{ }^{86} \mathrm{Sr}$ & ${ }^{87} \mathrm{Sr} /{ }^{86} \mathrm{Sr}$ & $\left({ }^{87} \mathrm{Sr} /{ }^{86} \mathrm{Sr}\right)$ & $\begin{array}{c}\mathrm{Sm} \\
(\mathrm{ppm})\end{array}$ & $\begin{array}{c}\mathrm{Nd} \\
(\mathrm{ppm})\end{array}$ & ${ }^{147} \mathrm{Sm} /{ }^{144} \mathrm{Nd}$ & ${ }^{143} \mathrm{Nd} / 144 \mathrm{Nd}$ & $\boldsymbol{\varepsilon}_{(\mathrm{T}=2,095 \mathrm{Ga})}$ & $\mathrm{T}_{\mathrm{CHUR}}(\mathrm{Ga})$ \\
\hline 799 & 190 & 2360 & 0,2329 & 0,71138 & $\mathbf{0 , 7 0 4}$ & 31,53 & 214,3 & 0,088999 & 0,511065 & $\mathbf{- 1 , 7 1}$ & $\mathbf{2 , 2 2}$ \\
\hline 800 & 210 & 1710 & 0,3552 & 0,717392 & $\mathbf{0 , 7 0 7}$ & 37,71 & 251,6 & 0,090663 & 0,511067 & $\mathbf{- 2 , 1 2}$ & $\mathbf{2 , 2 5}$ \\
\hline 813 & 210 & 2170 & 0,2799 & 0,711372 & $\mathbf{0 , 7 0 3}$ & 28,27 & 180,2 & 0,094897 & 0,511036 & $\mathbf{- 3 , 8 7}$ & $\mathbf{2 , 3 9}$ \\
\hline
\end{tabular}




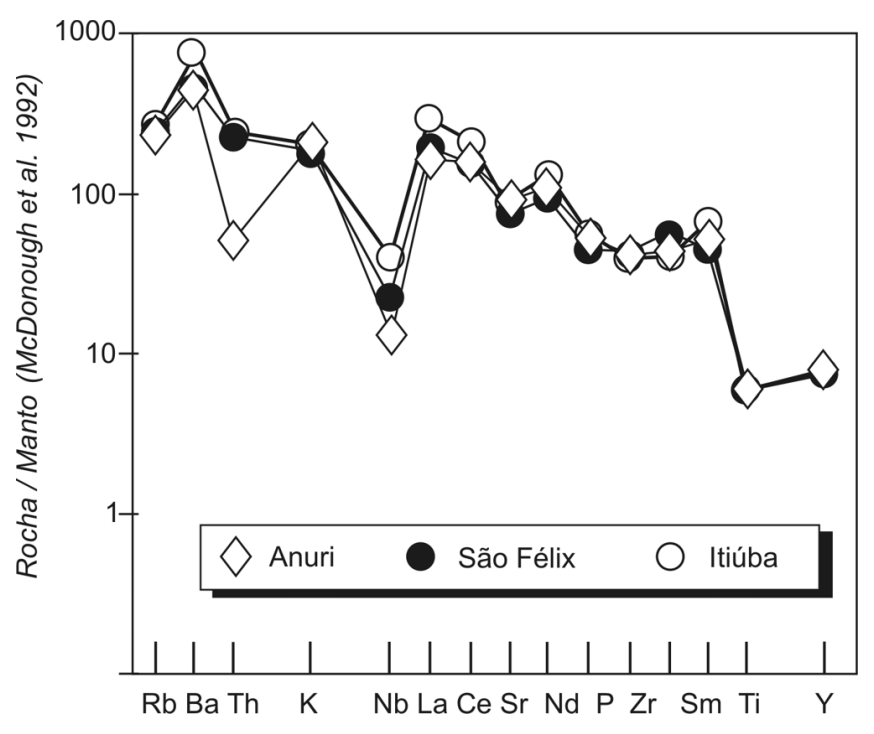

Figura 7 - Diagrama multielementar, normalizado pelo Manto Primitivo de McDonough et al. (1991) aplicado às médias dos tipos de rochas dos diques de Itiúba, São Félix e Anuri, a partir dos dados químicos de Conceição (1990), Rosa et al. (2001) e Conceição et al. (1996), respectivamente.

rentes diques os posicionam no campo do manto enriquecido de natureza EMI, o que associado aos dados geoquímicos levaram Conceição et al. (1997) a admitir uma fonte mantélica para esses magma. Estudos em maciços sieníticos neoproterozóicos (p.ex. Triunfo Ferreira et al. 1997 e Bom Jardim - Guimarães \& Da Silva Filho 1998) revelaram assinatura isotópica simi- lar, sugerindo que essa fonte mantélica permaneceu ativa até o período Neoproterozóico.

Por fim, a idade de cristalização $2095 \pm 4$ Ma do DAS, permite inferir - levando-se em conta aquelas disponíveis para os demais diques de sienito do leste da Bahia -, que eles tiveram suas intrusões sincrônicas a período de alívio das tensões regionais, após os movimentos de transcorrência que sucederam as colisões transamazônicas. Por outro lado, as razões isotópicas de $\mathrm{Sr}$ e Nd para esses diques apontam para uma fonte mantélica enriquecida, o que encontra suporte com a natureza alcalina e ultrapotássica inferida para os magmas responsáveis por essas rochas. Os baixos conteúdos de Ti(Ta)-Nb são indicativos de magmas mantélicos com assinatura de subducção. A reunião dessas informações permite supor que entre $2.095 \mathrm{Ma}$ e 2.100 Ma foi um período geológico favorável para baixas taxas de fusão mantélica sob o Cráton do São Francisco, responsáveis pela geração de magmas alcalinos ultrapotássicos, que aparentemente permaneceu ativo até o período Neoproterozóico.

Agradecimentos $\mathrm{O}$ desenvolvimento desta pesquisa foi possível graças aos recursos obtidos junto a Companhia Baiana de Pesquisa Mineral (CBPM) e a Fundação Apoio à Pesquisa no Estado da Bahia (FAPESB). HC e MLSR agradecem a CAPES pelas bolsas de PósDoutorado (França) e Doutorado-Sanduíche (Suíça), respectivamente. MLSR é bolsista Prodoc-CAPES e $\mathrm{HC}$ de produtividade em pesquisa MCT-CNPq. Os autores agradecem as sugestões dos revisores deste trabalho. Contribuição de número 210 do Laboratório de Petrologia Aplicada à Pesquisa Mineral do CPGGIGEO-UFBA.

\section{Referências}

Alkmim F.F. 2004. O que faz de um cráton cráton? O Cráton do São Francisco e as revelações almedianas ao delimitá-lo. In. V.Mantesso-Neto, A. Bartorelli, C.D. Carneiro \& B.B. Neves (orgs.) Geologia do Continente Sulamericano: Evolução da Obra de Fernando Flávio de Almeida. Beca, São Paulo, p. 17-34.

Barbosa J.S.F. \& Sabaté P. 2003. Colagem paleoproterozóica de placas arqueanas do Cráton do São Francisco na Bahia. Rev. Bras. Geoc., 33(sup 1):7-14.

Barbosa J.S.F., Correa Gomes L.C., Marinho M.M. \& Silva F.C.A. 2003. Geologia do segmento sul do Orógeno Itabuna Salvador-Curaçá. Rev. Bras. Geoc., 33(sup 1): 33-48.

Conceição H. \& Otero O.M.F. 1996. Magmatismo granitico e alcalino no estado da Bahia. Salvador, Sup. Geol. Rec. Min., 133 p.

Conceição H., Rios D.C., Rosa M.L.S., Davis D.W., Dickin A.P., Mcreath I., Marinho M.M. \& Macambira M.J.B. 2002. Zircon Geochronology and Petrology of AlkalinePotassic Syenites, Southwestern Serrinha Nucleus, East São Francisco Craton, Brazil. Int. Geol. Reviews, 44(2): 117-136.
Conceição H. 1990. Pétrologie du massif syénitique d'Itiúba: contribution à l'étude minéralogique des roches alcalines dans l'État de Bahia (Brésil). These de doctorat, Centre d'Orsay-França, Université Paris-Sud, 395 p.

Conceição H. 1993. Petrology of the syenites form the Salvador-Curaçá Mobile Belt (Bahia, Brazil): geodynamic significance. An. Acad. Bras. Sci., 65:18-32.

Conceição H., Martin H., Rosa M.L.S., Conceição R.V. \& Sabaté P. 1997. Alkali-potassic magmas generated by partial melting of an enriched-mantle source: example from the Paleoproterozoic plutonism, State of Bahia, NE Brazil. In: International Symposium on Granites and Associated Mineralizations, Salvador, Ext. Abs., p. 108-109.

Conceição H., Rosa M.L.S., Macambira, M.J.B., Marinho M.M., Scheller T. \& Rios D.C. 2003. 2,09 Ga idade mínima da cristalização do Batólito Sienítico Itiúba: um problema para o posicionamento do clímax do metamorfismo granulítico (2,05-2,08 Ga) no Cinturão Móvel Salvador-Curaçá. Rev. Bras. Geoc., 33(4):395-308.

Conceição H., Oliveira O.M.C., Martin H., Rosa M.L.S., Conceição R.V. \& Plá Cid J. 1996. Petrologia do mag- 
matismo alcalino-potássico com afinidade lamprofírica e assinatura de subducção no sul do estado da Bahia: Maciço Sienítico Anurí. Geoch. Bras., 11(2):171-186.

Evensen N.M., Hamilton P.J. \& O’Nions R.K. 1978. Rareearth abundances in chondrilic meteorites. Geochim. Cosmochim. Acta, 42:1199-1212.

Faure G. 1986. Principles of Isotopic Geochemistry. John Willey \& Sons, New York. 589 p.

Ferreira V.P., Sial A.N., Long L.E. \& Pin C. 1997. Isotopic signature of Neoproterozoic to Cambrian ultrapotassic syenitic magmas, Northeastern Brazil: evidence for an enriched mantle source. Int. Geol. Reviews, 39:660669.

Figueiredo M.C.H. 1981. Geoquímica das rochas metamórficas de alto grau do nordeste da Bahia - Brasil. In: H.A.V. Inda, M.M. Marinho \& F.B. Duarte (eds.), Textos Básicos da Geologia e Recursos Minerais do Estado da Bahia, SME/CPM, v.4, p. 1-71.

Guimarães I.P. \& Da Silva Filho A.F. 1998. Nd- and Sr-Isotopic and $\mathrm{U}-\mathrm{Pb}$ geochronologic constraints for evolution of the shoshonitic Brasiliano Bom Jardim and Toritama Complexes: evidences for a transamazonian enriched mantle under Borborema Tectonic Province, Brasil. Int. Geol. Reviews, 40:500-527.

Jordt-Evengelista H., Peres G.G. \& Macambira M.J.B. 2000. $\mathrm{Pb} / \mathrm{Pb}$ single zircon dating of paleoproterozoic calc-alkaline/alkaline magmatism in the southeastern São Francisco Craton region, Brazil. Rev. Bras. Geoc., 30(1):174-176

Le Bas M.J., Le Maitre R.W., Streckeisen A. \& Zanettin B. 1986. A chemical classification of volcanic rocks based on the total alkal-silica diagram. J. Petrol., 27:745-750.

Le Maître R.W., Bateman P., Ducek A., Keller J. Lameyre J., Le Bas M.J., Sabine P.A., Schmid R., Sorensen H., Streckeisen A., Wooley A.R. \& Zanettin B. 2002. A classification of igneous rocks and glossary of term. Blackwell Scientific Pub., London. 193 p.

Ludwig K.R. 2001. Isoplot/Ex 2.49. Berkley Geocronology Center, 43 p.

McDonough W.F., Sun S., Ringwood A.E., Jagoutz E. \& Hofman A.W. 1991. Rb and Cs in the earth and moon and the evolution of the earth's mantle. Geochim. Cosmoch. Acta. Ross Taylor Simposium vol.

Mascarenhas J.F. 1979. Evolução geotectônica do Pré-Cambriano do estado da Bahia. In: H.A.V. Inda (ed.) Geologia e Recursos Minerais do Estado da Bahia. Textos Básicos. SME/CPM, Salvador, Bahia, v.2, p. 57-165.

Padilha A.V. \& Melo R.C. 1991. Evolução geológica da Folha Pintadas. In: Geologia da região centro norte oriental do estado da Bahia. Folha Pintadas (SC.24-Y-D-V), Brasília-DF, DNPM/CPRM, PLGB, p. 129-157.

Pearce J.A, Harris N.B.W. \& Tindle A.G. 1984. Trace element discrimination diagrams for tectonic interpretation of granitic rocks. J. Petrol., 25:956-983.

Rios D.C. 2002. Granitogênese no Núcleo Serrinha: Geocronologia e Litogeoquímica. Tese de Doutorado, Ins- tituto de Geociências, Universidade Federal da Bahia, $235 \mathrm{p}$.

Rollison H. 1993. Using Geochemical Data. Logman, Singapore. $352 \mathrm{p}$.

Rosa M.L.S., Conceição H., Oberli F., Meier M., Martin H., Macambira M.J.B., Santos E.B., Paim M.M., Leahy G.A.S. \& Leal L.R.B. 2000. Geochronology (U-Pb/ $\mathrm{Pb}-\mathrm{Pb})$ and isotopic signature $(\mathrm{Rb}-\mathrm{Sr} / \mathrm{Sm}-\mathrm{Nd})$ of the $\mathrm{Pa}-$ leoproterozoic Guanambi batolith southwestern Bahia State (NE Brazil). Rev. Bras. Geoc., 30(1):62-65.

Rosa M.L.S. 1994. Magmatismo shoshonitico e ultrapotássico no sul do cinturão móvel Salvador-Curaçá maciço de São Félix: geologia mineralogia e geoquímica. Dissertação de Mestrado, Instituto de Geociências, Universidade Federal da Bahia, 241 p.

Rosa M.L.S. \& Conceição H. 1995. Caracterização petrográfica mineralógica e geoquímica do Maciço Sienítico de São Félix Bahia. Geoch. Bras., 9(2):201-219.

Rosa M.L.S. 1999. Geologia geocronologia mineralogia litogeoquímica e petrologia do Batólito Monzo-Sienítico Guanambi-Urandi (SW-Bahia).Tese de Doutorado, Instituto de Geociências, Universidade Federal da Bahia, $186 \mathrm{p}$.

Rosa M.L.S., Conceição H., Macambira M.J.B., Scheller T., Martin H. \& Leal L.R.B. 2001. Idade Pb-Pb e assinatura isotópica $\mathrm{Rb}-\mathrm{Sr}$ e $\mathrm{Sm}-\mathrm{Nd}$ do magmatismo sienítico. Rev. Bras. Geoc. 31:397-400.

Silva A.B., Liberal G.S., Grossi Sad J.H., Issa Filho A., Rodrigues C.S. \& Riffel B.F. 1988. Geologia e petrologia do Complexo Angico dos Dias (Bahia, Brasil), uma associação carbonatítica. Geoch. Bras., 2:81-108.

Silva Filho M.A, Moraes Filho O., Gil C.A.A \& Santos R.A. 1974. Geologia da Folha SD.24-Y-D. In: Projeto Sul da Bahia - Relatório Final. MME/DNPM - Convênio DNPM/CPRM. 81 p.

Silva Filho M.A., Bomfim L.F.C., Santos R.A., Leal R.A., Santana A.C. \& Brito Filho P.A. 1977. Projeto Baixo São Francisco e Vaza Barris - Relatório Final. DNPM/ CPEM. 283 p.

Silva L.C., Armostrong R., Delgado I.M., Pimentel M.M., Arcanjo J.B., Melo R.C., Teixeira L.R., Jost H., Cardoso Filho J.M. \& Pereira L.H.M. 2002. Reavaliação da evolução geológica em terrenos pré-cambrianos brasileiros com base em novos dados U-Pb SHRIMP. Parte 1: limite centro-oriental do Cráton do São Francisco. Rev. Bras. Geoc., 32(4):501-512.

Teixeira L.R. 1997. O Complexo Carnaíba e a Suíte São José do Jacuípe no Cinturão Móvel Salvador-Curaçá (Bahia Brasil): petrologia geoquímica e potencial metalogenético. Tese de Doutorado, Instituto de Geociências, Universidade Federal da Bahia, 243 p.

Manuscrito CSF-02 Submetido em 12 de maio de 2006 Aceito em 01 de março de 2007 